\title{
Contiguous or Border Languages and Their Teaching in Europe
}

\author{
Irina Moira Cavaion \\ Research Institute in Koper, Slovenia \\ irina.cavaion@zrs-kp.si
}

\begin{abstract}
Contiguous or border languages have a complex nature and still lack a scientific and shared definition. Numerous documents, recommendations, and frameworks encourage European border areas - which represent $40 \%$ of the territory in the Union and concern $30 \%$ of the European population - to introduce or enhance the teaching of neighbouring languages from nursery school through to university. This article will provide a reflection on the difficulty of building an overview of teaching neighbouring languages in European countries. It will also present a few successful cross-border neighbouring languages teaching projects and conclude by asserting the importance and urgency of beginning a scientific debate on the denomination of border languages and on national and European linguistic policies.
\end{abstract}

Keywords: border language teaching, language policy, historical multilingualism, national minorities, European border areas

\section{Introduction}

Contiguous or border languages are characterised by their multidimensional nature, lack of scientific definition in the field of applied linguistics (Cavaion 2016), and consequently by their challenging identification within educational language policies and procedures within each European country. This article will focus on the aspects most closely connected to educational language policies.

Starting from a reflection on the sociolinguistic nature of contiguous or border languages and proceeding with an analysis of European documents that discuss the importance of their teaching, we will guide the reader towards a reflection on the current difficulty of creating a teaching framework for these European languages. However, the examples of crossborder didactic-methodological projects - specifically on the Dutch-BelgianGerman, French-German and Italian-Slovenian borders - that we will describe, will show and significantly emphasise the best qualities in teaching contiguous or border languages, which are shown (European Commission 2017) to be effective tools for economic and social growth.

It will conclude by asserting the importance and urgency of beginning 
a scientific debate on the denomination of border languages and national language policies dedicated to them, identifying this type of education, and mostly its distribution and the sharing of it, as concrete action for the development of active citizenship and intercultural sensitivity development, as well as in the fight against neo-nationalism that has defined Europe over the last decade.

\section{Contiguous or Border Languages: A Difficult (Missing) Definition}

As their name suggests, contiguous languages are spoken in geographically close, neighbouring territories. In the field of linguistics, contiguous languages are being studied in the framework of contact linguistics. There, the focus is set on phenomena such as language contamination, interference and calque, often in studies related to bilingualism and multilingualism. Contiguous languages are linked to the concept of sprachbund (Trubetzkoy 1923; 1930) namely a linguistic area, interpreted as the area where geographically adjacent languages converge, and that show structural similarities not always or not at all dependent on their degree of kinship with related languages. Linguistic areas are not, in any case, linguistically, socially, and historically uniform (Thomason 2000). These studies, however, are not followed by any reflection on education or language policy.

It is indeed important to consider that in Europe, in most cases, what we define here as 'border languages' corresponds to the languages of the socalled national minorities, in other words languages of linguistic communities that, for historical reasons (mostly wars), were divided from their kin nation, consequently finding themselves straddling two national territories in accordance with rules ratified by international treaties that defined their territoriality and protection, thus becoming, de facto, transnational languages with very different functions and characteristics in the society they belong to, due to their historical journey and the related local language policies (Williams 1991; Klatt 2013; Cavaion 2016).

Border languages, in the context of national minorities, belong in a meaningful way to communities which can benefit from schools using their own language of instruction. The issue instead becomes clear in the relationship with the majority community which sets up teaching of those languages in its own schools, not following international laws that oblige its presence, but following local language policies that are often the real and direct product of policies that are varyingly inclined and varyingly sensitive to understanding and promoting the importance of teaching the language of the national minority within the majority community. 
This is why contiguous or border languages, when taught in majority community schools, are often identified by the name of the language of the neighbouring country. For instance, in Italy in the border area with France, 'Insegnamento della lingua francese/French language teaching;' in France, at the border with Germany 'Enseignement de la langue allemande/German language teaching.' As a result of this, they do not give any clues as to what their role and function is in the area, and sometimes come with misleading information. This can be seen in the case of Slovenian language teaching in Italian-medium schools, in the province of Trieste, where it is defined as 'Teaching of Slovenian as a foreign language [European]' (Cavaion 2018). This is contrary to Italian language teaching in the Slovenian coastal area, at present defined as 'Teaching of Italian as a second language,' where it assumes both the meaning of the language of the territory and the neighbouring country.

Therefore, the denomination of border languages in the areas where they are spoken lacks a definition of that language's role and function in relation to the territory that hosts (or is inhabited by) that language, the relationship with which the choice should therefore depend upon, according to Europe (European Commission 2017), of making such teaching useful, alongside the linguistic customs of its citizens. In fact, in the neutrality of categorising this type of instruction cannot be demonstrated if they take into consideration a distinction between standard language and eventual regional variety which proves to be functional in the local society. That is, from a neutral categorising we cannot understand whether local language educational policy assumes the responsibility of meeting the needs of 'a border community' and if an open dialogue with the users is promoted for co-creation of definitions of border language education which we would hope for.

If the lack of a shared denomination for contiguous or border languages in the field of applied linguistics and in the local educational language policies in the border regions is unhelpful to the research, the study of documentation related to their development by the European Union is, on the other hand, enlightening.

\section{Contiguous or Border Languages: Old and New References from Europe} The European Council and European Commission declare contiguous or border languages as a 'category', denominating them as neighbouring languages, stressing their important transnational function (Council of Europe 2005).

Europe has not dedicated much documentation to the border areas, their languages and the teaching of these languages. Nevertheless, such docu- 
mentation does depict particularly rich and propositional reading with the only weak point being their non-binding nature. ${ }^{1}$

The first document to consider border languages was the 'Recommendation Rec (2005)3 of the Committee of Ministers on Teaching Neighbouring Languages in Border Regions' (Council of Europe 2005), a document which adopts as principle good neighbourly relationships, in the context of conventions and agreements of transborder cooperation, for the means of promoting plurilingualism in a pan-European context. The document takes on the objective of developing educational language policies by safeguarding or, as necessary, introducing, the instruction of a neighbour's language and their culture. The document's background is very interdisciplinary, that is, very attentive to the studies that consider border areas from a linguistic, historical, and political perspective. That includes:

- recommendations which take into account the results from research of modern languages and fields of language teaching and plurilingualism;

- the emphasis on the value of cultural diversity but also taking into account the transborder cooperation impeded by such linguistic and cultural diversity;

- the adoption of a principle of good neighbourliness as a base for a more free and tolerant Europe;

- examples of a rich experience of transborder educational cooperation as 'good practice' to prepare citizens of a united Europe;

- a cross reference with the European Charter for Regional or Minority Languages with, in reality, only a reference to Art. 14, dedicated to transnational cooperation.

The document represents the only European recommendation that specifically takes into account neighbour languages and the importance of mastering them. It discusses the importance of:

- stablishing conditions that would allow teaching institutions of transborder regions at all levels to safeguard/introduce the teaching of neighbouring languages;

\footnotetext{
${ }^{1}$ In fact, Europe includes Recommendations and Communications or Communication proposals, all documents which have the function of guiding member states whilst not obliging them to accept the proposed actions.
} 
- encouraging different actors in transborder cooperation in the teaching and language sectors to become involved in transborder cooperation projects;

- trying to establish language reciprocity, while cooperating with a neighbouring country, that would make space for national languages but also for other languages spoken in the border area involved, be they regional languages or of the minority community.

The recommendation highlights two important, desirable aspects for border areas: respect for the diversity of existing languages along the boundaries - diversity which is impossible to generalise due to the diverse typologies of linguistic situations that characterise transborder regions (Klatt 2013) - and, within the sphere of diversity, the principle of reciprocity, in which it can be imagined that every country puts into effect every possible strategy to avoid any possibility of exercising power connected to the status of the involved languages.

Albert Raasch's study (2002) Europe, Frontiers and Languages certainly inspired the writing of the aforementioned Recommendation. It represents an analytical and thorough investigation of European border areas and an inspiring vision of the role that teaching and learning of a neighbour's language could have in border areas. According to the author, if on one hand Neighbouring Languages should be understood and 'read' through the analysis of their 'origins, movements, changes and transfers that determine the way in which people interpret them' (Raasch 2002, 10), on the other hand their teaching demonstrates a common will to overcome old barriers.

We consider it important to cite from this study the importance given to the necessity of developing awareness, mostly among teachers and students. It is a matter both of cultural awareness - that is, related to the role of their territory, of their region, of the importance of mastering the languages of their territory - and political awareness, in this case referring mostly to the teachers who have to undertake the responsibility of co-creating meanings of language education in border areas. The study also points out the necessity of creating institutional and administrative networks capable of providing the foundation of learning and teaching specifically adapted to the situation and to the circumstances of the border, and it indicates cross-border cooperation as a foundational strategy for linguistic education based on close contact.

Another interesting document, of great symbolic value, although not specifically addressed to border languages, is the study by Amin Maalouf, 
A Rewarding Challenge: How the Multiplicity of Languages Could Strengthen Europe (European Commission 2007). It reports the proposition of the European Commission on the necessity of developing 'bilateral relationships among the people of the European Union,' mostly where conflicts have divided adjacent countries. Here we will quote it in full (pp. 16-17):

Europe has arisen from several centuries of conflict between its nations and primarily between neighbours. Accordingly, to learn the language of a partner who happens to be a former - enemy is very important, both for its symbolic value as well as for its practical advantages. If there is to be greater cohesion between the countries of the European Union, it is not enough for them to simply all belong to the same entity, the bilateral links between each country and each partner must be cemented by powerful ties based in particular on the special place occupied, for the citizens of each country, by the language of the other.

The document highlights the importance of learning languages other than English, such as neighbouring languages, not for utilitarian criteria but rather following principles based on 'cultural affinity' (personal adoptive language) in order to improve the quality of relationships in terms of 'efficiency of exchanges' but also, or even more importantly, for 'the subtlety of human contact' and to reinforce 'the intensity and the solidity of people-to-people within our vast European family' (European Commission 2007, 10).

For the purposes of this essay it is important to refer also to some recent documents, also redacted by the European Council, of which the first one - 'Proposal for a Council Recommendation on a Comprehensive Approach to the Teaching and Learning of Languages' (European Commission 2018) without solely addressing border areas, promotes their potential by proposing important actions on integration and connection between the specificities of the border context and the wider context of social and cultural growth of Europe itself and its citizens, mostly for the purpose of mobility, and starting from transborder areas of language contact. This document, in fact, considers the promotion of competencies capable of responding to the need of mobility and to an approach that would favour a strong connection between academic learning and experience beyond academia.

A second document entirely dedicated to European border areas - 'Boosting Growth and Cohesion in EU Border Regions' (European Commission 2017) - presents to us a vision of Europe, through numbers, of its transborder areas that prompts us to reflect on the situation. 
The border regions within the European Union, according to the document, occupy $40 \%$ of its territory and represent $30 \%$ of the population. It's worth stating that this is 150 million people, who generate $30 \%$ of Gross National Product and are characterised by a dynamic situation of transborder commuting, above all for professional reasons (European Commission 2017, 2). The document, based on a socio-economic study of border areas, reports underdevelopment and points towards recovery thanks to actions which include the strengthening of multilingualism in the same areas.

Border regions are described as places in which the process of European integration should be seen in a particularly positive way, or rather that it should be possible to carry out daily activities (studying, working, training, providing care or doing business) independently of the existence of national borders, but instead it has been identified that 'the inflexible use of different languages on both sides of a border increases the administrative burden as well as hampers meaningful exchanges between public administrations and individuals' (European Commission 2017, 13).

Concluding, a useful study for forming a picture of the situation of such an improvement in multilingual education in the border regions for the purposes of their social and economic emancipation (among others) could be to verify the application of Recommendation (2005)3 on the instruction of border languages in border regions, that is, if it has been cited or not among the reference documents for the construction of local language policies and neighbouring language curricula.

Europe does not only have internal borders, but also several 'external' ones, which put it in contact with nations, ethnicities, and languages which open towards other cultural realities, not always close by. Here, the historical complexities and intercultural relations and policies make it all the more complex.

And it is precisely with regard to the complexity of these areas where concrete action is still, and more than ever, necessary for their emancipation, that we write about the importance of learning and teaching border or neighbouring languages as a potential and necessary instrument for social integration and intercultural communication and for the necessity of creating common, shared, and widespread teaching.

\section{Teaching Border Languages in Europe: A General, As Yet Unfeasible Picture, with Examples of Good Practices}

We have tried to refer to a European document which summarises the situation of language teaching in all member states of the European Union. It 
refers to a redacted report from 2017 from the Eurydice ${ }^{2}$ network entitled Key Data on Teaching Languages at School in Europe (Eurydice 2017). The report gives information on the languages studied in European schools: what age students start to study a first and second foreign language, what level of knowledge the students should reach at the end of compulsory schooling, and how linguistic competencies are measured. In the document we searched for contiguous, border, or neighbouring languages amongst the categories of languages taught, but they are not mentioned. In the introduction to the Eurydice Report there is a list of languages that are classified as official in various European countries, including minority languages but without distinguishing between regional languages and national ethnic minority languages situated along the borders. This appears to be new evidence for the necessity of giving a name to the teaching of neighbouring country languages which could associate it with a recognisable category which would allow the recognition of its presence or absence.

Therefore we can, up to this point, state that at the moment it is not possible to provide a general picture of teaching of border languages at a European level because this category of linguistic teaching does not exist, although it is very likely that it is practised in a widespread and unregulated way, as in the examples we report below relative to good practices of neighbouring language teaching and learning.

\section{Border/Neighbour Language Teaching in European and Local Cross-Border Projects: CICERO, Euregioschool, French Strategy, Contatti!}

If official terminology, scientific studies and the application of European recommendations show us a glimpse of how much more work there is to be done, a positive and constructive example of contiguous/border/neighbour language teaching comes from a single programme that has not only harnessed the potential of this type of language teaching but has certainly also served as guidance for the programmes that have followed.

It is the case of the CICERO project, which was proposed as a coordination centre for the teaching of border languages at European level, and led from 2000 to 2003 by Ruud Halink (Netherlands) and by Albert Raasch (Ger-

\footnotetext{
${ }^{2}$ The Eurydice network - made up of national units situated in various European countries and coordinated by the Education, Audiovisual and Culture Executive Agency EACEA - among its duties works to understand and explain the organisation and the way in which the different European educational systems work, providing descriptions of the national systems of education (see http://ec.europa.eu/eurydice).
} 
many), Gabriele Schmitz-Schwamborn (Netherlands), Ulrike Schwarz (Germany), and Juri Valge (Estonia), to spread good practices in border language teaching in the transborder areas of the participating subjects. It was a European project that provided for the establishment of an online database, which contained descriptions of the project, practical advice, names of experts and news which could contribute to improving the knowledge of said teaching. ${ }^{3}$

After CICERO and its portal, in the Meuse-Rhine Euroregion in the 2000s, the Euregioschool project developed under the guidance of some representatives from the same CICERO project. Euregioschool aims to put schools situated along the Belgian-German-Netherlands border in touch with each other to undertake learning activities in the reciprocal language for the development and practical application of a model for the acquisition of precocious languages and to continue through cross-border contact. The students' learning progress is connected to the European reference framework through their linguistic portfolio and checked methodically.

The Euregioschool uses a trilingual website (German, French, Dutch) and a Teaching Guide. On the website, ${ }^{4}$ the following text can be found:

The Euregioschool is not a school in the true sense of the word, but an approach that tries to systematically integrate the teaching of languages with a partner school in the neighbouring country. By linking neighbouring language lessons with an exchange, learning neighbouring languages gains a dimension that is very often lacking in conventional foreign language teaching: authenticity.

It is precisely this concept of authenticity of language learning that brings together examples of programming here described. The geographical closeness of the schools involved in the reciprocal language learning allows communicative and genuine relational exchanges, that is a usefulness of the language learnt, and an effective co-creation of syllabi derived from the direct experience of contact between classes. Euregioschool for example, other than from a methodological perspective, takes on border language teaching with marked attention to curricula and the continuity between primary and secondary school.

${ }^{3}$ The CICERO Project is no longer available online; however, minimal documentation can still be found in the archives of the European Centre for Modern Languages in Graz (https://www.ecml.at/Home/tabid/59/language/en-GB/Default.aspx).

${ }^{4}$ See http://www.euregioschool.eu/de/schulung-lehrer. 
A second geographical area that has demonstrated both policy and didactic attention towards the teaching of border languages is the region of Saar, on the border of France and Germany, through the strategy known as French Strategy. ${ }^{5}$ This is much more than an inter-institutional project. Rather, it is a very ambitious regional strategy that certainly represents an important point of reference for other border regions in Europe.

The objective of the French Strategy is to render the Saar region a multilingual federal state within one generation - before 2043 - or rather that French, together with other European languages, becomes widely used together with German as the mother and official language of the state. This would render the Saar region, where multilingual teaching is already a consolidated practice, the only multilingual federal state in Germany. In fact, a series of bilingual nursery schools and 20 binational and trinational courses that are offered by the German-French University (DFH/UFA) already exist. Thanks to the excellent specialist and intercultural education that they receive, 70 percent of all those who graduate find a job within three months in a transborder area, characterised by many bilingual entrepreneurs (see the project site mentioned above).

In the south-east of Europe, along the Italian-Slovenian border, in the coastal area, we can find the project Contatti! which uses a ministerial website, a theoretical framework (Cavaion 2016), a methodological guide (Cavaion 2019), and promotes a specific tool for reflection on transborder encounters, that is a digital interactive autobiography. ${ }^{6}$ The Contatti! project, funded by the Slovenia Research Agency (ARRS), is based on the pedagogical model for the teaching of border languages CoBLaLT (Contact-based(neighbouring)Language-Learning-and-Teaching) (Cavaion 2016) which envisages the learning of an adjacent country's language through the methodological use of contact with speakers of that language, in a situation of virtual, mutual understanding that comes before, prepares, encourages, and accompanies the face-to-face meeting, or rather many meetings. The act of really seeing one another actually reflects the ultimate goal and the motivational lever, both from the perspective of language learning and as a relational act for the linguistic and intercultural progress and the growth of active citizenship, as carried out through the act of learning each other's culture and language.

In this area, despite the fact that the programme of mutual learning mo-

\footnotetext{
${ }^{5}$ See https://www.saarland.de/229459.html.

${ }^{6}$ See http://contatti.si/home.page.
} 
bilised students, teachers, supervisors, and families, and brought important positive results in terms of motivation for neighbouring language learning and in terms of pedagogic innovation (Cavaion 2016; 2019), the project is hampered by the lack of transborder language policies, more precisely by the lack of language policy on the Italian side of the border - in the Friuli Venezia Giulia region - that would potentially emancipate the region and its citizens through the widespread introduction of teaching its regional and border languages.

\section{Conclusions}

Europe demonstrates that it has taken on both the importance as well as the presence of programming regarding the teaching of border/neighbouring country languages in some transborder areas, by promoting policies that include the category of border languages in documents regarding both the border areas (Council of Europe 2005; European Commission 2017) and the global approach of European language education (European Commission 2018).

However, such proposals are not applied or applicable, in part due to the non-binding nature of the aforementioned documents, but essentially for a lack of recognition at the single state member level of the concept of a 'border/neighbouring country language' and therefore, also of a conscious and coherent teaching of these languages. On the other hand, examples of good practices exist which could serve as a guidance for the foundations of a new field of study within applied linguistics research.

Opening a scientific debate on the nature and the possible specific methodologies for the instruction of contiguous/border/neighbouring (country) languages is, in our opinion, urgent. This is more important than ever in a Europe that is suffering from protectionism that risks frustrating the efforts of a European Union not only based on cultural ethnic linguistic diversity but inspired by this, enriched for example by the opportunity for social, intercultural, and economic growth that the ethnic-linguistic border crossroads can offer if they are appreciated in the local educational language policies.

\section{References}

Cavaion, Irina Moira. 2016. Let's contact! An Introductory Study to CoBLaLT. Koper: Annales.

- 2018. 'Aree di confine e formazione degli insegnanti di LS: lo sloveno nelle scuole nell'area di confine italo-slovena.' Scuola e Lingue Moderne 56 (7-9): 13-18. 
2019. Guida alla didattica del contatto: insegnare ed apprendere le lingue del vicino attraverso il contatto transfrontaliero. Koper: Annales. https:// www.zrs-kp.si/wp-content/uploads/2020/02/Contatti_2019_ITA.pdf

Council of Europe. 2005. 'Recommendation Rec (2005)3 of the Committee of Ministers on Teaching Neighbouring Languages in Border Regions.' Council of Europe, Strasbourg.

European Commission. 2007. A Rewarding Challenge: How Language Diversity Could Strengthen Europe. Luxembourg: Office for Official Publications of the European Communities.

- 2017. 'Boosting Growth and Cohesion in EU Border Regions.' COM(2017) 534 final, European Commission, Brussels.

- 2018. 'Proposal for a Council Recommendation on a Comprehensive Approach to the Teaching and Learning of Languages.' COM(2018) 272 final, European Commission, Brussels.

Eurydice. 2017. Key Data on Teaching Languages at School in Europe. Luxembourg: Publications Office of the European Union.

Klatt, Martin. 2013. 'National Minorities as a Model for Cross-Border Integration: Lessons from Schleswig.' In Integration und (trans-)regionale Identitäten, edited by Joachim Beck and Birte Wassenberg, 301-19. Stuttgart: Franz Steiner.

Raasch, Albert. 2002. L'Europe, les frontières et les langues: guide pour l'élaboration des politiques linguistiques éducatives en Europe - de la diversité linguistique à l'éducation plurilingue: étude de référence. Strasbourg: Conseil de l'Europe.

Thomason, Susan. 2000. 'Linguistic Areas and Language History.' Studies in Slavic and General Linguistics 28: 311-27.

Trubetzkoy, Nikolai S. 1923. 'Vavilonskaja bašnja i smešenie jazykov' Evrazijskij vremennik 3:107-24.

— 1930. 'Proposition 16. Über den Sprachbund.' Actes du premier congrès international des linguistes à la Haye, du 10-15 avril 1928, 17-18. Leiden: A. W. Sijthoff.

Williams, Colin H. 1991. Linguistic Minorities, Society, and Territory. Philadelphia: Multilingual Matters. 